\title{
Loucura e abuso de substâncias psicoativas: Desinstitucionalização e as vicissitudes da parentalidade
}

Adilane dos Santos Barbosa. Universidade Federal da Bahia

Vládia Jamile dos Santos Jucá. Universidade Federal da Bahia

Mônica de Oliveira Nunes de Torrenté. Universidade Federal da Bahia

Carla Mariana Sousa de Jesus. Escola Bahiana de Medicina e Saúde Pública

Ueslei Solaterrar da Silva Carneiro. Universidade Federal do Rio de Janeiro

\section{Resumo}

O exercício da parentalidade por sujeitos com um sofrimento psíquico, com ênfase para os que são socialmente reconhecidos como loucos e para os que desenvolveram uma relação de dependência para com as substâncias psicoativas, é um tema pouco problematizado. O objetivo principal desse artigo foi analisar como o exercício da parentalidade contribui na história de vida desses sujeitos para o restabelecimento dos laços e para a reinserção social. Trata-se de um estudo comparativo de casos no qual se utilizou a História de Vida. Participaram do estudo dois homens, por meio de entrevistas gravadas e transcritas. As entrevistas produzidas foram analisadas a partir de três categorias, visando realizar a análise do discurso. As categorias - "Os desafios da parentalidade na loucura e na dependência de substâncias psicoativas"; "A reinserção a partir da reconstrução de uma nova família"; e "Construindo Caminhos" - serviram como eixos para discussão dos dados produzidos na pesquisa.

Palavras- chave: desinstitucionalização; parentalidade; loucura.

\begin{abstract}
Madness and abuse of psychoactive substances: Deinstitutionalization and the vicissitudes of parenting. The exercise of parenting by people with psychic suffering, with an emphasis on those who are socially recognized as crazy and those who have developed a relationship of dependence on psychoactive substances, is a little problematized subject. The main objective of this article was to analyze how the exercise of parenting contribute to the life history of these subjects for these establishments of bonds and social reintegration. This is a comparative case study in which the History of Life was used. Two men participated in the study, through recorded and transcribed interviews. The interviews produced were analyzed from three categories, aiming at the discourse analysis. The categories - "The challenges of parenting in the madness and dependence of psychoactive substances"; "Reinsertion from there construction of a new family"; And "Building Paths" - served as axes for discussion of the data produced in the search.
\end{abstract} Keywords: deinstitutionalization; parenthood; madnes.

\section{Resumen}

Locura y abuso de sustancias psicoactivas: Desinstitucionalización y las vicisitudes de la parentalidad. El ejercicio de la parentalidad por individuos con un sufrimiento mental, con énfasis en aquellos que están socialmente reconocidos como locos y aquellos que han desarrollado una relación de dependencia con sustancias psicoactivas, es un tema poco cuestionado. El objetivo principal de este estudio fue analizar cómo el ejercicio de la parentalidad contribuye a la historia de vida de estos sujetos para la restauración de los lazos y la reintegración social. Se trata de un estudio comparativo de casos en los que se utiliza la historia de vida. El estudio incluyó a dos hombres, a través de entrevistas grabadas y transcritas. Se analizaron las entrevistas a partir de tres categorías, con el objetivo de llevar a cabo el análisis del discurso. Categorías - "Los desafíos de la paternidad en la locura y la dependencia de sustancias psicoactivas"; "La reintegración de la reconstrucción de una nueva familia"; y "La construcción de caminos" - sirvió como ejes para la discusión de los datos producidos en el estudio.

Palabras clave: desinstitucionalización; parentalidad; locura. 
Mediante o contexto de sofrimento psíquico, analisar como ocorre a construção da parentalidade é uma oportunidade para refletirmos acerca desse processo que implica em transformações físicas, psíquicas e sociais. Assim, se faz pertinente esclarecer a compreensão adotada aqui acerca desse conceito. $O$ estudo da parentalidade envolve a análise "... dos vínculos de parentesco e dos processos psicológicos que se desenvolvem a partir daí" (Solis-Ponton, 2004, p. 29).

A parentalidade se fabrica com ingredientes complexos. Alguns deles são coletivos, pertencem à sociedade como um todo, mudam com o tempo, são históricos, jurídicos, sociais e culturais. Outros são mais íntimos, privados, conscientes, ou inconscientes, pertencem a cada um dos pais enquanto pessoas; enquanto futuros pais, pertencem ao casal, à própria história familiar do pai e da mãe (Moro, 2005, p. 259).

Deste modo, e para fins da discussão a ser realizada neste artigo, a parentalidade é compreendida como um laço que transcende os aspectos biológicos de ter gerado um filho:

o processo de tornar-se pai e tornar-se mãe é um longo percurso que se inicia muito antes do nascimento de um filho. No entanto, pretendemos argumentar que, se este percurso se inicia na infância de cada um dos pais, o nascimento de um filho produz uma mudança irreversível no psiquismo parental, podendo, inclusive, auxiliar na retificação de sua história infantil (Zornig, 2010, p. 456).

De modo mais particular, é importante considerar o exercício da parentalidade por parte das mulheres e de homens que carregam consigo o estigma da loucura. No imaginário popular, está naturalizada a ideia dos ditos "loucos" como perigosos, infantis, ou como pessoas que não se responsabilizam pelos seus atos (Foucault, 1975). Por conseguinte, os considerados loucos, não poderiam nem responder por si próprios nem tampouco ter sob sua tutela uma criança ou adolescente.

A despeito do que a sociedade espera do louco, é importante ressaltar que, na prática, a loucura não priva o sujeito de todas as suas capacidades (Cohen \& Salgado, 2009). A pessoa em sofrimento psíquico estabelece um modo diferente de relação com o mundo, sendo a loucura uma "condição de existência" (Tenório, 2001). Socialmente, o estigma que marca a loucura (Goffman, 2008) faz com que pais e mães que comportam esta marca sejam entendidos como um risco para o bem-estar dos filhos. O estigma dos pais estende-se também aos filhos que, por sua vez, são discriminados em consequência dessa filiação.

$\mathrm{Na}$ transversalidade entre parentalidade e abuso/ dependência de substâncias psicoativas (SPA), outra dimensão da pesquisa realizada, um primeiro ponto a se considerar são os diversos tipos de uso: o uso experimental, eventual, recreativo ou social e o uso caracterizado pela dependência (Medina, Nery, \& Flach, 2014). No caso deste artigo, estaremos tratando do abuso/ dependência que se caracteriza por ser um uso incontrolável, compulsivo e intenso que pode estar, ou não, associado ao uso de múltiplas substâncias.

Muchata e Martins (2010) apontam que a dependência das substâncias comprometeria a parentalidade e a saúde mental dos seus filhos. Para esses autores, a dependência das drogas se torna um fator que dificultaria a manutenção das funções parentais. Sinalizam ainda que confrontar-se com essa fragilidade e com a impossibilidade de cumprir com essas funções desencadearia situações de recaídas ou agudizaria situações de consumo continuado. "Nestes casos, em situações clínicas, assiste-se muitas vezes a uma parentificação das crianças, que são investidas como prestadoras de cuidados aos seus progenitores, durante o seu tratamento". (Muchata \& Martins, 2010, p.48). O mesmo fenômeno é apontado por Béguier (2004), autor segundo o qual algumas crianças desenvolvem uma "hipermaturidade", diante da impossibilidade do meio de responder adequadamente as suas necessidades.

Nos casos em que o sofrimento psíquico intenso está presente, incluso os casos de abuso/ dependência de substâncias psicoativas, o laço entre os pais e a criança encontra-se realmente em risco. No entanto, maior é o risco quanto maior for a falta de assistência e rede social de suporte. Cada caso deveria ser analisado cuidadosamente para evitar intervenções que agudizam o sofrimento dos pais e introduzem a criança em um contexto de institucionalização.

Com recorrência, a perda do poder familiar ocorre de forma compulsória sem uma reflexão sobre os impactos e prejuízos que tal medida possa ter. No cenário atual brasileiro, observam-se casos de mães usuárias de substâncias psicoativas que são afastadas de seus bebês ainda na maternidade. Essas ações ocorreram tomando como referência o discurso jurídico que entende a necessidade de intervenção se for constatado risco ao bem-estar físico e psíquico da criança. Cabe o questionamento sobre até que ponto essa medida funciona realmente como protetiva e que ações foram 
realizadas, em termos de oferta de cuidado no campo da saúde e assistência social, para que a retirada da guarda seja a efetivamente a última alternativa.

O próprio Estatuto da Criança e do Adolescente (ECA) da lei $n^{\circ} 8.069$, de 13 de julho de 1990 apresentava em seu Art. 19 um respaldo legal para a retirada da guarda nos casos de filhos de usuários de substâncias psicoativas: "Toda criança ou adolescente tem direito a ser criado e educado no seio da sua família e, excepcionalmente, em família substituta, assegurada a convivência familiar e comunitária, em ambiente livre da presença de pessoas dependentes de substâncias entorpecentes". O artigo 19, no entanto, foi reformulado e reapresentado nos seguintes termos, segundo a lei $n^{\circ}$ 13.257, de 2016: "É direito da criança e do adolescente ser criado e educado no seio de sua família e, excepcionalmente, em família substituta, assegurada a convivência familiar e comunitária, em ambiente que garanta seu desenvolvimento integral" (Art. 25). A mudança na apresentação se fazia necessária, afinal em praticamente todas as famílias brasileiras, algum consumo de "substancias entorpecentes" acontece (a exemplo do álcool). O mais importante, entretanto, é que a reformulação protege a criança cujos pais fazem um uso problemático de substâncias psicoativas porque reforça a importância de sustentar o laço referente a parentalidade, o qual só deve ser rompido em situações específica, nas quais o acolhimento institucional se apresenta como última alternativa.

É necessário entendermos que o exercício da parentalidade é em si mesmo um desafio. Nos casos em que há um sofrimento psíquico por parte de um dos pais, o desafio é ainda maior, porque a necessidade de uma rede social de suporte se faz mais presente. As questões clínicas não podem ser desconsideradas. Por exemplo, nas situações mais agudas de sofrimento psíquico, bem como no uso problemático de substâncias psicoativas, em função da condição psíquica na qual o pai (ou a mãe) se encontra, é possível que a criança seja percebida como um elemento intrusivo ou persecutório, através de uma construção delirante. Mesmo quando isto não acontece, os cuidados necessários com a criança podem sofrer prejuízo.

Cabe, então, pensarmos que uma rede social ${ }^{1}$ de suporte e uma integralidade no cuidado de pais e filhos seria uma alternativa nestas circunstâncias. De preferência, o apoio e a assistência deveriam existir previamente, em particular, nos casos em que as questões de saúde mental já se fazem presentes. A implementação da Rede de Atenção Psicossocial (RAPS), instituída pela portaria 3.088 , de 22 de dezembro de 2011, por sua configuração e perspectiva política de desinstitucionalizar e (re) construir laços, não pode desconsiderar a questão da parentalidade que, para alguns homens e mulheres, é de fundamental importância na definição de um lugar para si no campo social.

Gostaríamos de lembrar que a reconstrução ou mesmo a construção dos laços sociais possíveis para cada sujeito é ao mesmo tempo uma tarefa clínica e um compromisso social e político assumido pela reforma psiquiátrica. A reforma pode ser pensada como uma tentativa de dar à loucura outra resposta social, não asilar, evitando a internação como destino inexorável e visando à manutenção do louco no laço social (Tenório, 2002).

A reforma tem em seu cerne o desafio da desinstitucionalização que diz respeito ao agenciamento de um novo lugar para a loucura no campo social. Alverga e Dimenstein (2006) ressaltam que é preciso superar os "desejos de manicômios", termo cunhado por Machado e Lavrador (2001). Tais desejos não estão circunscritos pelos muros do hospital psiquiátrico: "Partimos do princípio de que formas manicomiais de expressão ou de subjetividade permeiam todo o espaço-tempo, atravessam nossas ações" (Alverga \& Dimenstein, 2006 p. 300).

Alverga e Dimenstein (2006) destacam que a desinstitucionalização é muito mais uma lógica que envolve a desconstrução do paradigma da racionalidade cartesiana do que a mera retirada das pessoas do hospital psiquiátrico. Isto quer dizer que mesmo na rede substitutiva corremos o risco de reproduzir relações de poder que relançam o louco no lugar da infantilidade e da periculosidade; lugar de um resto social que por desafiar as normas da razão, precisa ser mantido sob tutela, sendo alvo de controle e de marginalização.

Quando pensamos em trabalhar os laços sociais, nesta perspectiva, é preciso considerar que não podemos reduzir a desinstitucionalização a um conjunto de ações através das quais tornaríamos os loucos aptos para o convívio social ou estaríamos concedendo a estes o direito de serem cidadãos. É preciso agenciar o dito louco e o usuário de substância psicoativa para que ele possa reclamar a sua própria cidadania e para que cada um descubra os caminhos, através das estratégias que se mostrarem potentes em cada caso, para refazer seus laços, inclusive, os de parentalidade. 
Loucura e abuso de substâncias psicoativas: Desinstitucionalização e as vicissitudes da parentalidade

\section{Metodologia}

Escolheu-se como fundamento metodológico para a realização desse estudo a História de Vida, por se tratar de uma abordagem que permite ao pesquisador ter acesso ao significado que o sujeito dá ao que foi vivido. Destarte, a história de vida é um relato de uma trajetória que é singular a cada sujeito, contada a partir de sua própria experiência.

Queiroz (1991) define a história de vida como: "o relato de um narrador sobre sua existência através do tempo, tentando reconstruir os acontecimentos que vivenciou e transmitir a experiência que adquiriu" ( $p$. 6). Nesse sentido, o sujeito ao contar sua história tem a possibilidade de reeditá-la.

De acordo com Gaulejac (citado por Silva, Barros, Nogueira, \& Barros 2007), o método da história de vida tem como objetivo promover o acesso a uma realidade que ultrapassa o narrador. Isto é, através do relato da história de vida, contada de forma singular por cada sujeito, é permitido ao pesquisador ter acesso a conteúdos por meio dos quais ele tenta compreender o universo do qual o sujeito faz parte.

Trabalhamos com a história de vida, a partir do estudo de dois casos, com o objetivo de realizar uma análise comparativa entre um homem que vivenciou o estigma da loucura e outro com histórico de abuso de substâncias psicoativas, a fim de perceber as particularidades (desafios e retomada) da parentalidade nos dois casos. Na eleição dos sujeitos da pesquisa, procuramos pessoas que tivessem filhos e que estivem vivenciando a desinstitucionalização.

Para fins do estudo, a desinstitucionalização foi pensada a partir da trajetória dos participantes que passaram por uma situação de sofrimento psíquico grave e desagregadora, precisaram do apoio de instituições de saúde mental, vivenciaram a ruptura dos seus laços familiares e de trabalho, mas conseguiram um reposicionamento no campo social, onde o estigma já não os aprisionava. Em seus percursos, romperam com os constrangimentos impostos por categorias como "louco" ou "drogado", e passaram a ser reconhecidos por papéis conquistados e desempenhados no campo social como o de "trabalhador" e o de "pai".

O termo "estudo de caso" vem de uma tradição de pesquisa médica e psicológica, que se refere a uma análise detalhada de um caso individual que explica a dinâmica e a patologia de uma doença dada; o método supõe que se pode adquirir conhecimento do fenômeno adequadamente a partir da exploração intensa de um único caso. Adaptado da tradição médica, o estudo de caso tornou-se uma das principais modalidades de análise das ciências sociais (Becker, 1999, p.117).

Foram realizados alguns encontros com os participantes da pesquisa a fim de ter acesso à história de vida dos envolvidos, bem como foram feitas várias observações do cotidiano dessas pessoas, devidamente registradas em diários de campo. Para realização das entrevistas, foi utilizado um roteiro semiestruturado, com uma questão central disparadora: pode me contar a sua história?

$\mathrm{Na}$ análise a ser descrita logo a seguir, foi fundamental cotejar os dados produzidos nas entrevistas com os registros do diário de campo, os quais forneciam elementos contextuais fundamentais para um melhor aprofundamento dos elementos apontados pelos entrevistados em suas falas. Pela observação participante, percorremos, com os entrevistados, seus territórios, visitamos lugares de trabalho, bem como familiares e amigos que eles quiseram nos apresentar. $O$ que nos foi contado durante as entrevistas pode ser cotejado com os relatos daqueles que compõem a rede social dos sujeitos colaboradores da pesquisa. $E$, para além do que foi explicitamente enunciado, a observação das interações, bem como do modo pelo qual cada um habita o território onde vive, propiciou um entendimento mais rico e complexo do momento no qual os entrevistados se encontravam por ocasião da pesquisa.

O estudo que deu origem a esse artigo seguiu os procedimentos preconizados pelo Conselho Nacional de Saúde. O mesmo foi submetido e aprovado pelo Comitê de Ética. Neste sentido, foi formulado um Termo de Consentimento Livre e Esclarecido (TCLE) que foi assinado pelos participantes de modo que, somente após o consentimento dos sujeitos, as entrevistas foram gravadas.

Para analisar as narrativas produzidas, trabalhamos a partir da técnica de análise do discurso que visa a compreensão do funcionamento, dos princípios de organização e das formas de produção social do sentido (Minayo, 1996, p.211), lembrando que:

O sentido não está "colado" na palavra, é um elemento simbólico, não é fechado nem exato, portanto sempre incompleto; por isso o sentido pode escapar. $\mathrm{O}$ enunciado não diz tudo, devendo o analista buscar os efeitos dos sentidos e, para isso, precisa sair do enunciado e chegar ao enunciável através da interpretação (Caregnato \& Mutti, 2006, p.681). 
A fim de preservarmos a identidade e o anonimato dos participantes, estabelecemos nomes fictícios. Segue uma breve apresentação das histórias de vida dos dois colaboradores do estudo:

Caetano: nasceu no interior da Bahia, 40 anos, vem de uma família de cinco filhos, sendo ele o segundo. É pai de quatro filhos dos quais três, um menino de 18 anos e duas meninas uma de 15 anos e a outra de 5 anos, foram do seu primeiro casamento. Recentemente teve um filho de outro relacionamento. Seu filho mais novo tinha 1 ano por ocasião da pesquisa. Do primeiro casamento, Caetano destaca a traição da companheira. A história de seus pais também foi marcada por traição. Sua mãe tinha relacionamentos extraconjugais e, em função de uma paixão, sai de casa, levando apenas a filha mais velha. Caetano fica com o pai que, pouco a pouco, vai dando os filhos. Aos 11 anos, foi entregue aos cuidados de uma senhora que morava em Salvador. Nesta idade, foi posto para vender picolé em uma região portuária e, graças a sua circulação nesta área da cidade, passa a trabalhar como marinheiro. A primeira crise ocorreu alguns meses após a morte do pai, vítima de assassinato. Caetano encontrava-se com 21 anos e já estava casado. A morte do pai é um marco em sua vida. Seu adoecimento teve início; em busca de tratamento, recebeu diagnósticos errados, inclusive, uma suspeita de cardiopatia foi levantada. Com o agravo do quadro clínico, ele passou a escutar vozes e perambular pelas ruas, descuidando-se por completo. Perdeu os movimentos da perna e ficou impossibilitado de andar. Naquela ocasião, foi a esposa quem o levou para o CAPS. Neste equipamento, recebeu tratamento e o diagnóstico de esquizofrenia. Sua principal cuidadora era a esposa e, por ser responsável pela gestão da medicação, por vezes, ela o dopava a fim de sair para as festas. A recuperação de Caetano, em sua narrativa, aparece muito associada ao encontro com um grupo de teatro da cidade, destinado a pessoas com sofrimento psíquico, mas que não está vinculado a nenhum serviço em particular, bem como a descoberta de sua capacidade de compor músicas. A arte foi um elemento crucial na sua trajetória de recuperação e de reinserção. Atualmente, Caetano tem uma relação conflituosa com sua família e uma relação ambivalente com sua mãe. Trabalha como oficineiro no CAPS de sua cidade de origem, além de ser ator (faz parte de um grupo de teatro), é professor de teatro em uma escola pública e trabalha como palhaço. Seus filhos moram com as respectivas mães, mas vão visitar e passar dias na casa de Caetano.
Renato: nasceu em Salvador, 52 anos, é o segundo filho, tendo uma irmã mais velha. Casado há 20 anos, sua esposa tem cinco filhos de outro relacionamento. Relata muito desejo de ter um filho, porém sua esposa fez a retirada do útero o que impossibilita uma gestação. Dessa forma, cuida e adota como filha a neta da esposa, hoje, com 9 anos. Renato morou com os pais até os 6 anos de idade quando, então, os pais se separam. Na versão contada pelo pai, a mãe de Renato o traiu e, por isso, ele tomou as crianças e as mantém afastadas da mesma. Com 8 anos, o pai o levou para São Paulo e entregou aos cuidados de uma família. Aos 9 anos, teve o primeiro contato com o álcool. Essa família adotiva tinha 10 filhos e um dia um dos filhos do casal tentou abusar sexualmente de Renato. Em virtude dessa tentativa de estupro, ele foge de casa e vai viver na rua. Nesse momento, na rua, ele conta que conhece todo tipo de drogas: thinner, cola etc. Ele é encontrado pelo pai, na rua, que o traz de volta a Salvador para morar com a madrinha. Porém, após a morte do padrinho tudo muda novamente na vida de Renato. Ele sai de casa e vai morar com a irmã em uma casa alugada pelo pai. Com16 anos, vai morar na rua em Salvador e fica até os 21 anos. Hoje trabalha como redutor de danos. Passou por algumas internações em casas de recuperação para usuários de substâncias psicoativas. Com 43 anos, começou a fazer tratamento no CAPS no qual está até hoje.

A partir do trabalho de campo e dos elementos apontados nos relatos foi possível construirmos três categorias de análise: Os desafios da parentalidade na loucura e na dependência de substâncias psicoativas; A reinserção a partir da reconstrução de uma nova família; Construindo Caminhos.

\section{Análise e discussão dos resultados}

\section{Os Desafios da Parentalidade na Loucura e no Abu- so/Dependência de SPA}

A parentalidade envolve aspectos sociais, psicológicos e culturais que despertam diversos sentimentos, principalmente quando se carrega o estigma do louco ou do usuário de SPA. Deste modo, nessa categoria almejamos identificar e analisar as principais implicações e dificuldades enfrentadas pelos participantes no exercício da parentalidade.

Pensando nisso, trazemos o caso de Renato que manifesta muito desejo de ser pai, porém sua esposa retirou o útero, o que impossibilitou uma gestação. Ele relata que sua esposa teve cinco filhos de outro 
casamento. Uma das filhas engravidou e, segundo ele, teve uma depressão pós-parto, o que fez com que ele e a esposa tomassem para si os cuidados e criação da menina. Nesse caso, ele pôde tornar-se pai com a neta da sua esposa, "adotada" informalmente por ele como filha. A menina também o "adota" enquanto pai. Um caso ilustrativo da perspectiva segundo a qual a parentalidade acontece como um processo de co-construção e investimento mútuo (Zornig, 2010). A criança, ao mesmo tempo, recebe cuidados e parentaliza seus cuidadores.

É importante destacar o quanto, para Renato, o tornar-se pai é atravessado por elementos importantes de sua história, ele nos diz: "... eu desejava muito ter um filho para aliviar minha alma". Em consonância, ele expressa diversas vezes o desejo em exercer a parentalidade de forma mais efetiva. Todavia, sua esposa, que se tornou evangélica, não permite que Renato saia para passear sozinho com sua enteada e cria dificuldades no convívio entre eles. Isto intensifica o sofrimento psíquico por ele apresentado, levando a um aumento do uso da maconha. Vejamos seu relato: "É, quando não estou bem, sinto uma tristeza, penso em desistir, aumento o uso". Quando questionado sobre o que lhe causava tristeza, ele afirma:

Com o preconceito da minha mulher com relação a minha filha, principalmente por ela ser cristã e eu ainda fazer uso de maconha. Não ter autonomia com a minha filha me entristece muito... Ontem nós tivemos uma discussão porque ela diz que tudo de errado que a menina faz é culpa minha (Renato).

\section{Completa dizendo:}

Tenho vontade de me separar, porque eu nunca deixei de usar maconha e o problema da minha mulher é todo esse: não deixa eu sair com a menina para nenhum lugar. Eu achava que ia ter o direito de pai. Eu só me considero pai quando a criança me chama. Se eu me separasse dela antes (menciona a filha) ia se desapegar e eu não ia mais vê-la, aí eu tive medo, mas agora a menina diz: eu vou com meu pai. Se eu não tivesse (menciona a filha), não estava mais com ela. (Renato)

O caso de Renato nos convida a pensar qual o lugar da filha para este pai, sabendo que tal lugar se ergue a partir da experiência deste enquanto filho através de sua história marcada por separações e, algumas vezes, experiências de desamparo. E, ainda, em que lugar a menina é colocada na relação do casal. Nosso propósito aqui não é realizar uma discussão clínica, portanto, não aprofundaremos neste último ponto. Outrossim, dentro do campo de reflexão delimitado para este artigo, é relevante destacar o movimento através do qual a companheira de Renato o desautoriza a estar com a menina, utilizando como justificativa central seu histórico de abuso de substâncias psicoativas, não obstante, há alguns anos, ele faça apenas um uso recreativo da Cannabis.

Na contramão do que apontam Muchata e Martins (2010), autores que defendem a ideia de que pais com uma relação de abuso/dependência de SPAs teriam dificuldades no relacionamento com seus filhos, tendo pouco envolvimento afetivo para com os mesmos, o trabalho com Renato desvelou uma situação contrária: seu movimento ocorre justo na tentativa de manter o laço e a convivência com a enteada que tomou como filha. Ocupar o lugar de pai lhe possibilita ressignificar, e de certo modo, reparar a experiência familiar vivida em sua infância. Além do mais, é um importante elemento no trabalho que realiza para reposicionar-se no campo social.

Em relação aos casos dos ditos loucos, é relevante trazer para a discussão que, nos quadros de um sofrimento psíquico grave, o sujeito em alguns momentos não se encontra em condições de responder às exigências que lhe são impostas. Nesse sentido, o trabaIho a ser desenvolvido precisa ser na direção de criar possibilidades e condições para que esse sujeito possa exercer a parentalidade.

Nosso outro colaborador do estudo, Caetano, como mencionado anteriormente, tem quatro filhos, sendo que todos moram com as mães. Quando Caetano chegou ao CAPS para dar início ao tratamento, relata que não conseguia andar, as pessoas davam-Ihe banho, cortavam seu cabelo e unhas. Ficou irreconhecível, segundo conta. Nessa situação, sua esposa é quem cuidava e dava o suporte que ele precisava, inclusive, nos cuidados com os filhos já que Caetano não estava em condições para desempenhar o que Houzel (2004) designou como uma "prática da parentalidade" (tarefas cotidianas), que seria um dos três eixos discutidos por esse autor em torno da parentalidade. Os outros eixos seriam: o exercício da parentalidade - entendido aqui com um caráter mais jurídico, como sendo o exercício de um direito; a experiência da parentalidade fala da experiência subjetiva de vir a se tornar pai ou mãe. Diante da situação relatada, como dar conta de cuidar, alimentar, educar os filhos? Exercer a prática da 
parentalidade se torna difícil nessas condições. Nesses casos se faz necessário uma rede social de suporte para auxiliar e passar por esse momento de fragilidade psíquica.

Com o filho mais novo, fruto de outro relacionamento, ele nos conta que recorreu à justiça para tentar obter a guarda da criança. Entretanto, teve seu pedido recusado sem uma justificativa clara, sem abertura para negociações, ou para uma análise cuidadosa das condições de cada um dos pais. A situação relatada nos faz refletir sobre o quanto esses sujeitos se encontram em um lugar de impotência e desvantagem social, tendo o seu direito menos valorizado e defendido em virtude do seu quadro psíquico, além da tendência de alguns operadores da justiça de reproduzirem questões de gênero.

Caetano atualmente apresenta melhores condições de cuidar da criança, porém a justiça entende que é "natural" o filho permanecer com a mãe, mesmo que esta não disponha dos recursos que seriam ideais para o cuidado e suporte a criança. Caetano em seu relato verbaliza que já encontrou o menino preso em casa sozinho, ou mesmo desnutrido, sem os cuidados necessários que um garoto de um ano requer. Ele nos diz que a justiça não foi na casa dele nem da mãe da criança para avaliar as condições de cada um a fim de decidir pela guarda. A decisão foi rápida e pautou-se no direito da criança de permanecer com a mãe, desconsiderando inclusive que o bem-estar do menor deveria ser o norteador das decisões nestes casos.

Percebe-se que nas decisões judiciais sobre a guarda dos filhos ainda há uma forte influência do "mito do amor materno" (Banditer, 1980/1985). "Tradição" que, nos casos nos quais a saúde mental está envolvida, será reforçada pelos estigmas que pairam sobre o louco e o usuário de substâncias psicoativas (no caso, as ilícitas). Os princípios constitucionais de igualdade entre pai e mãe tendem a ser desconsiderados. Caetano, não obstante a decisão judicial, persiste no movimento de tentar conseguir a guarda do filho.

\section{A Reinserção a partir da (Re) Construção de uma Nova Família}

A partir das histórias de vida, foi comum a referência à família de origem na busca pela reconstrução de uma nova família. O que nos fez trazer para reflexão nessa categoria o papel da parentalidade como operador de laço social e a posição dos nossos participantes enquanto filhos para a construção do lugar de pais.
Renato conta que, quando conheceu sua esposa, estava muito mal e viu nessa relação a possibilidade de (re) construção de uma família:

Estava muito mal. E aí eu vi a possibilidade de ter uma família que não fosse igual à que eu tinha. Eu tinha 33 anos e estava no uso abusivo de drogas. Eu não percebia que havia um agravamento, mas outras pessoas percebiam (Renato).

$\mathrm{Na}$ análise desse discurso, nota-se que a construção de uma nova família passa pelo desejo de que essa seja diferente e que não traga os resíduos deixados pelo sentimento de abandono e desamparo advindos da família de origem. Assim, Zornig (2010) pensa que a concepção de um filho coloca em questão aspectos do narcisismo dos pais. "... a criança ocupa no psiquismo parental, principalmente sua função 'reparadora', ou seja, de suturar as feridas narcísicas de seus próprios pais" (Zornig, 2010, p.457). Podemos pensar no filho, no caso de nosso entrevistado, como um símbolo importante que pode significar uma forma de auxílio na "retificação de sua história infantil" (Zornig, 2010).

No que tange à trajetória de Caetano, ele demonstra um sentimento de pesar ao narrar sua história. Ele vem de uma família de cinco filhos, sua mãe traía seu pai e, em função de uma paixão, sai de casa. Caetano fica com o pai que, pouco a pouco, vai dando os filhos. Por sentir a dor do abandono, pensa muito em seus filhos e faz o possível para ser um pai presente. Relata:

Eu chorava muito por causa dos meus filhos, porque eu nunca pensei na minha vida em conviver sem os meus filhos. Eu nunca pensei na minha vida sair sem os meus filhos. Porque eu fui abandonado, eu sei a dor que é viver sem pai e sem mãe. É muito grande. Eu rodei por várias casas, não foi em uma casa só não. E eu nunca pensei isso com meus filhos (Caetano).

Mesmo não estando próximo dos filhos, por morar no interior, Caetano participa ativamente da educação e dos cuidados com as crianças. Em relação à educação e a tentar passar o que aprendeu com seu pai, ele relata:

Tudo que meu pai me ensinou, o pouco que eu passei com ele, eu ensinei a meus filhos. Tem uma coisa muito antiga que hoje ela (se referindo à filha) não gosta: eu ensinei a dar bênção aos mais velhos. (Caetano) 
Caetano traz para sua experiência de parentalidade sua vivência enquanto filho, buscando repetir e transmitir o modelo parental que foi aprendido. Caetano conta que, ao perceber-se em um lugar em que coisas erradas estão acontecendo, ele tende a se afastar. Assim, o que é correto e incorreto, certo e errado, são coisas muito importantes para ele. Durante as entrevistas, ele sempre voltava a esse ponto. A retidão moral atribuída por Caetano a seu pai e com a qual se identifica, garante sua filiação e é esta herança que ele deseja transmitir a seus filhos. Nesse sentido, Zornig(2010) nos sinaliza que:

O processo de filiação se inicia antes do nascimento do bebê, a partir da transmissão consciente e inconsciente da história infantil dos pais, de seus conflitos inconscientes, da relação com seus próprios pais, que colorem sua própria representação sobre a parentalidade (p. 457).

Para falarmos da parentalidade e sua transversalidade com a loucura e dependência/abuso das SPAs, é necessário nos remetermos à ideia tão preciosa de herança trazida por Derrida. Derrida (2004) em seu diálogo com Roudinesco sinaliza que todos somos herdeiros de uma história que nos antecede, contudo, ao herdá-la, temos a possibilidade de escolha. "Não é apenas aceitar essa herança, mas relançá-la de outra maneira e mantê-la viva. Não escolhê-la (pois o que caracteriza a herança é primeiramente que não é escolhida, sendo ela que nos elege violentamente), mas escolher preservá-la viva" (p.12). Nesse sentido, não estaríamos obrigados a aceitá-la tal como é, pois "Um herdeiro não é apenas alguém que recebe, é alguém que escolhe, e que se empenha em decidir". (p.17) Assim, os filhos necessitam conviver com essa herança que lhe é dada, porém fazendo suas próprias escolhas.

Nos dois casos estudados, o pai aparece com um destaque importante. Para Lebovici (2004) a lembrança dos cuidados parentais (regras, obrigações, interditos) é base e servem de referência para os pais no processo de tornarem-se pais. Ambas as histórias são marcadas por trajetórias de desgaste dos laços com as famílias de origem. Renato acabou na rua e teve que se virar. Caetano, por sua vez, não foi para a rua, mas também foi deixado pela mãe e entregue pelo pai a outra família e teve que buscar sua própria sobrevivência. A família aparece como ponto central nas narrativas.

A despeito dos sofrimentos e dificuldades na busca pela reconstrução de uma nova família, deparamo-nos com um vivido que parece ainda não ter sido elaborado. É um sofrimento transgeracional, são muitos não-ditos que geram sofrimento até hoje na vida desses sujeitos.

Foi possível observar nas narrativas que a experiência da parentalidade atualiza questões relativas à própria vida dos sujeitos da pesquisa, como sou/fui como filho, por exemplo. As histórias de vida e a relação com seus filhos também (re) atualizam uma situação de desamparo.

\section{Construindo Caminhos}

Para Alverga e Dimenstein (2006), no território nacional predominam mobilizações sociais no campo da saúde mental que partem do pressuposto que a reabilitação psicossocial restituirá a cidadania do louco. Contudo, esses autores acreditam que a luta pela reforma psiquiátrica se torna limitada se baseada no princípio da reinserção, pois as práticas cotidianas tornam-se muitas vezes cronificadoras.

sabe-se que a reforma deve buscar a emancipação, não meramente política, mas, antes de tudo, uma emancipação pessoal, social e cultural, que permita, dentre outras coisas, o não-enclausuramento de tantas formas de existência banidas do convívio social; que passe a encampar todas as esferas e espaços sociais; que permita um olhar mais complexo que o generalizante olhar do igualitarismo; e busque a convivência tolerante com a diferença. (Alverga \& Dimenstein, 2006, p. 303).

Destarte, partimos nessa categoria da ideia de empoderamento e emancipação desses sujeitos, que foram subjugados e marginalizados pelos estigmas. Nossos entrevistados apresentam uma trajetória de um sofrimento psíquico intenso, que, a despeito de todas as limitações, conseguiram reorganizar suas vidas. No caso de Caetano, dois espaços artísticos são promotores de saúde e de laço social: a música (é compositor) e o teatro. A arte teve um lugar importantíssimo, sendo um elemento crucial e um ponto de virada na sua recuperação. Ele nos conta: "Pense aí, uma pessoa no chão e levantar... Fui eu. Mas além do teatro o que me levantou muito foi à música" (Caetano). Na história de Caetano, a arte foi a forma encontrada por ele de equilibrar-se com o mundo e consigo mesmo.

Além da arte, Caetano também trabalha no CAPS de sua cidade como oficineiro. $\mathrm{Na}$ verdade, ele realiza diversas atividades desde ajudar nas oficinas, dar apoio ao segurança, ajudar na cozinha, caso seja necessário, e faz muito o trabalho territorial, como visitas 
domiciliares às pessoas que não conseguem ir ao CAPS, ou realizando ações que visem à desconstrução e desmistificação da imagem do louco como perigoso. Sobre seu trabalho no CAPS, ele nos diz: "Todos ficam bestas porque eu estou trabalhando lá. E não sabem que quem me colocou lá foi eu mesmo". (Caetano)

Ele nos conta que, quando começou a trabalhar no CAPS, ninguém conhecia sua história de vida. Após algum tempo, foi compartilhando sua vivência nas oficinas como uma forma de mostrar para os demais que é possível superar as limitações e os impedimentos impostos pelo adoecimento.

Em várias situações, com destaque para as de difícil manejo na saúde mental, Caetano é convocado para ajudar. Em dada ocasião, passou um mês acompanhando os cuidadores escolhidos para trabalhar na recém-inaugurada residência terapêutica da cidade, a fim ajudá-los a aprender a lidar com pessoas cronificadas por uma longa história de institucionalização, egressos de um hospital psiquiátrico. Em uma visita a residência com Caetano, foi possível perceber a vinculação importante que mantém com os cuidadores e os moradores.

Caetano está envolvido no cuidado com pessoas que se encontram em sofrimento psíquico e conseguiu desenvolver ao longo do tempo estratégias para lidar com suas próprias dificuldades. Quando questionado sobre a continuidade do tratamento no CAPS e o uso de medicação, ele responde: "Estou bem, não tomo mais remédio... Não tomo nada. Terapia sou eu mesmo me suportar e ver que nada me derruba".Completa dizendo: "quando eu tomava o remédio ficava era Bajé [deprimido], parecendo que eu estava bêbado, cambaleando".

Em seu caso, a principal ferramenta terapêutica foi a arte, através do teatro, que possibilitou a reconstrução de laços e a conquista de uma posição na qual passou a ser reconhecido de modo positivo no campo social.

No caso de Renato, o movimento também foi de resgate da autonomia e um retorno ao circuito de trocas sociais. Quando questionado sobre o que foi a droga na sua vida, relata que:

A droga foi uma companheira nas horas mais difíceis da minha vida... Aos 9 anos eu vi no álcool uma droga que me tirava o vazio da minha mãe. A maconha me dá disposição para trabalhar, penso mais claro. Uma determinação. Eu me sinto bem. Me sinto legal. Eu aprendi a ser um apaziguador.
Foi através da militância e da disposição para ajudar o outro como forma de também se ajudar que Renato conquistou o "respeito" das pessoas e um trabaIho como redutor de danos. "É uma forma terapêutica quando ajudo as pessoas". (Renato)

Renato reconhece o lugar de cuidado que o CAPS teve em sua vida, pois foi a partir da inserção nesse espaço e da acolhida que recebeu que ele pôde se lançar rumo a um novo "propósito de vida". Conta:

... eu só consegui falar da minha vida depois do CAPS. O trabalho do CAPS ajudou na mudança da minha relação com a droga, o acolhimento e também uma das coisas que me ajudou foi chorar. $\mathrm{Na}$ oficina com os psicólogos aprendi a planejar minha vida aqui fora, traçar cursos e fui diminuindo o uso de drogas... (Renato).

Quando questionado sobre as pessoas que foram importantes para essa mudança em sua vida, ele nos relata que recebeu bastante apoio do CAPS:

Meus familiares não têm confiança, as pessoas que mais me ajudaram foram as pessoas do CAPS... A ajuda é mais fora da família do que dentro... Os usuários também me ajudam, pois quando faço esse trabalho [redutor de danos], estou resgatando a dignidade.

Os serviços de saúde mental, como o CAPS, devem ser locais de acolhimento que têm como ponto central a construção de laços que comportem as singularidades de cada um. Podemos perceber no discurso de Renato que o CAPS foi uma importante ferramenta na sua recuperação e na busca de autonomia. Ao ser perguntado sobre o momento que considerou decisivo em sua recuperação, Renato relata:

No CAPS, vi que ali era hora de... Principalmente porque fiz o curso de cidadania e direito de pessoas com problemas mentais e profissionalmente foi como redutor de danos. Ali vi uma maneira de me vingar das atrocidades que fazia. Vi uma maneira de lutar nessa discriminação. Quando eu fui para CAPS e conheci o que é cidadania... Lá foi o começo do meu propósito de vida, a entrada na militância e o convite pra ser redutor de danos (Renato).

Interessante notar como essas pessoas podem se transformar em agentes de promoção de saúde pela própria experiência. Não como um técnico, um psicólogo, mas como pessoas sensíveis que acessam os usuários de outro lugar. No percurso dos sujeitos da 
pesquisa, percebemos que, nos dois casos, eles voltam-se para a saúde mental agora em outra condição e com um lugar importante junto a outros usuários. Através das histórias narradas, eles nos mostram que é possível estar ali de outra forma.

Os CAPS aparecem nas narrativas dos entrevistados como um instrumento que auxilia na manutenção dos laços sociais e, consequentemente, nos vínculos referentes ao exercício da parentalidade, apesar de Caetano e de Renato avaliarem criticamente os serviços pelos quais passaram, identificando suas fragilidades. A despeito das limitações e dos problemas encontrados nos serviços substitutivos nos quais foram tratados, ambos apontam os CAPS como um lugar importante em termos de cuidado. Em especial, o vínculo com alguns profissionais e outros usuários foi fundamental para o apaziguamento do sofrimento e para a abertura de novas formas de estar no mundo.

\section{Considerações finais}

A parentalidade é um conceito difícil de ser trabalhado, principalmente pela sua multiplicidade de sentidos. Há escassez de estudos desenvolvidos no Brasil, principalmente no que diz respeito a sua transversalidade com a loucura e com o uso de substâncias psicoativas, a partir de uma perspectiva que não se restrinja aos efeitos patológicos da condição dos pais e seus efeitos no desenvolvimento dos filhos. Pensando nisso, buscamos nesse estudo dar visibilidade a essa problemática, promovendo uma reflexão sobre a experiência da parentalidade em sujeitos que sofrem com o estigma da loucura e por desenvolverem uma relação de dependência com substâncias psicoativas.

Nesse cenário, o ser pai aparece como um importante fator de promoção do laço social. Nesse sentido, os discursos que insistem em colocar o louco ou o usuário de substância psicoativa como piores pais do que os ditos "normais" nos preocupam. Esses discursos partem do princípio de que esses sujeitos não teriam "competências parentais", seriam "incapazes" para exercerem a parentalidade. Somos convocados a pensar: será que existiria uma condição "ótima", ou uma melhor maneira de ser pai ou mãe?

Nossos entrevistados tiveram suas histórias atravessadas pelo abandono, pela rua, pelo ter que se virar sozinho, pela falta de apoio da família. Adentrar nas histórias de vida desses homens/pais nos permite construir um novo olhar para com esses sujeitos. Um olhar para além da "doença". Nesse sentido, é necessário desconstruir velhas formas cristalizadas de estigma que não ajudam na (re) construção de um novo lugar social; só reforçam o imaginário social de que essas pessoas são "perigosas", "incapazes" ou "marginais".

Dessa maneira, consideramos que o movimento de (re) construção dos laços sociais e da desmistificação acerca da loucura e do usuário de SPA ressoa no bem-estar, na saúde mental e no empoderamento dessas pessoas que, com muita luta, no caso de nossos colaboradores, conseguem atravessar todo o cenário de descrença, estigma e passam a exercer outros papéis sociais.

Um aspecto que merece ser destacado é o papel dos CAPS na tessitura das histórias de vidas aqui relatadas. Os dois casos estudados apresentam trajetórias de desgaste dos laços com as famílias de origem e a passagem pelo CAPS, permitiu que eles construíssem uma rede de suporte social que possibilitasse um novo direcionamento.

Diante da dificuldade de encontrar na literatura brasileira textos que abordem a temática em questão, com o recorte específico sobre os homens/pais com sofrimento psíquico grave, é importante ressaltar que se faz necessário o desenvolvimento de novos estudos que aprofundem e deem visibilidade a essa que é uma questão tão silenciada. Escutar os filhos também emerge como um aspecto importante para que se possa compreender a história de vida desses sujeitos de uma forma mais ampla e para que seja possível realizar um trabalho integral no que diz respeito à assistência e cuidado desses pais e de seus filhos.

\section{Referências}

Alverga, A., \& Dimenstein, M. (2006) A Reforma psiquiátrica e os desafios da desinstitucionalização da Loucura. Interface: Comunicação e Saúde, 10(20), 299-316. doi: 10.1590/S1414-32832006000200003.

Banditer, E. (1985). Um amor conquistado: o mito do amor materno. (W. Dutra, Trad.). Rio de Janeiro: Nova Fronteira. (Obra original publicada em 1980)

Becker, H. S. (1999). Observação social e estudos de casos sociais. In H. S. Becker (Org.), Métodos de pesquisa em ciências sociais (pp. 117- 134). São Paulo: HUCITEC.

Béguier, I. (2004). A parentalidade em psiquiatria geral: do paciente aos pais. In M. C. Silva \& L. Solis-Ponton (Orgs.), Ser pai, ser mãe - parentalidade: um desafio para o terceiro Milênio (pp. 47-51). São Paulo: Casa do Psicólogo.

Caregnato, R. C. A., \& Mutti, R. (2006). Pesquisa qualitativa: análise de discurso Versus análise de conteúdo. Texto \& Contexto - Enfermagem, 15(4), 679-84. doi: 10.1590/ S0104-07072006000400017 
Cohen, C., \& Salgado, M. T. M. (2009). Reflexão sobre a autonomia civil das pessoas portadoras de transtornos mentais. Revista Bioética, 17(2), 221-235. Recuperado de http://revistabioetica.cfm.org.br/ index.php/revista_bioetica/article/view/163

Derrida, J., \& Roudinesco, E. (2004). Escolher sua herança. In J. Derrida \& E. Roudinesco. (Orgs.), De que amanhã... Diálogo. (pp. 9-31). Rio de Janeiro: Jorge Zahar

Fontes, E. M. M. (2010). Redes sociais e enfrentamento do sofrimento psíquico. In B. Fontes \& E. Fonte (Orgs.), Desinstitucionalização, redes sociais e saúde Mmental: análise de experiências da rReforma psiquiátrica em Angola, Brasil e Portugal (pp. 355 -388). Recife: UFPE.

Foucault, M. (1975). Doença mental e psicologia ( $1^{\text {a }}$ ed., L. Shalders, Trad). Rio de Janeiro: Tempo brasileiro.

Goffman, E. (2008). Estigma: notas sobre a manipulação da identidade deteriorada (4⿳a . ed., M. Nunes, Trad.). Rio de Janeiro: LTC. (Obra original publicada em 1988)

Houzel, D. (2010). As implicações da parentalidade. In M. C. P Silva \& L. Solis-Ponton (Org.), Ser pai, ser mãe - parentalidade: um desafio para o terceiro milênio (pp. 47-51). São Paulo: Casa do Psicólogo.

Lebovici, S. (2004). Diálogo Letícia Solis-Ponton e Serge Lebovici. In M. C. P Silva \& L. Solis-Ponton (Orgs.), Ser pai, ser mãe - parentalidade: um desafio para o terceiro milênio (pp. 21-27). São Paulo: Casa do Psicólogo.

Lei 8.069, de 13 de julho de 1990. (1990, 13 de julho). Dispõe sobre - Estatuto da Criança e do Adolescente e dá outras providências. Recuperado de http://www.planalto.gov.br/ccivil_03/LEIS/L8069. $\mathrm{htm}$.

Lei no 13.257, de 8 de março de 2016. (2016, 8 de março). Dispõe sobre as políticas públicas para a primeira infância e altera a Lei no 8.069, de 13 de julho de 1990 (Estatuto da Criança e do Adolescente). Recuperado de http://www.planalto.gov.br/ccivil_03/_ato20152018/2016/lei/L13257.htm.

Machado, L. D., \& Lavrador, M. C. C. (2001). Loucura e subjetividade. In L. D. Machado, M. C. C Lavrador, \& M. E. B Barros, (Orgs.), Texturas da Psicologia: subjetividade e política no contemporâneo (pp. 45-58). São Paulo: Casa do Psicólogo.

Medina, M. G., Nery, A., \& Flach, P. M. V. (2014). Políticas de prevenção aos usuários de substâncias psicoativas. In J. S. Paim \& N. FilhoAlmeida (Orgs.), Saúde coletiva: teoria e prática (pp. 479-496). Rio de Janeiro: MedBoock.
Minayo, M. C. S. (1996). A fase exploratória da pesquisa. In M. C. S Minayo (Org.), O desafio do conhecimento: pesquisa qualitativa em saúde (pp. 89-104). São Paulo - Rio de Janeiro: HUCITEC - ABRASCO.

Moro, M. R. (2005). Os Ingredientes da parentalidade. Revista Latinoamericana de Psicopatologia Fundamental, 8(2), 258-273. doi: 10.1590/1415-47142005002005.

Muchata, T., \& Martins, C. (2010). Impacto da toxicodependência na parentalidade e saúde mental dos filhos - uma revisão bibliográfica. Revista Toxicodependência, 16(1), 47-56. Recuperado de http:// www.sicad.pt/PT/RevistaToxicodependencias/Paginas/detalhe. aspx? itemld=492\&lista=SICAD_Artigos\&bkUrl=http://www.sicad pt/BK/RevistaToxicodependencias/Lists

Portaria no 3.088, de 23 de dezembro de 2011. (2011, 23 de dezembro). Institui a Rede de Atenção Psicossocial para pessoas com sofrimento ou transtorno mental e com necessidades decorrentes do uso de crack, álcool e outras drogas, no âmbito do Sistema Único de Saúde (SUS). Recuperado de http://bvsms. saude.gov.br/bvs/saudelegis/gm/2011/prt3088_23_12_2011_ rep.html.

Queiroz, M. I. (1991). Relatos orais: do "indizível" ao "dizível". In M. I. Queiroz (Org.), Variações sobre a técnica de gravador no registro da informação viva. (Vol. 7, pp. 1-26) São Paulo: T. A. Queiroz.

Silva, A. P., Barros, C. R., Nogueira, M. L. M., \& Barros, V. A. (2007). "Conte-me sua história": reflexões sobre o método da história de vida. Mosaico, 1(1), 25-35. Recuperado de https://seer.ufmg.br/ index.php/mosaico/article/view/4344

Solis-Ponton, L. (2004). A construção da parentalidade. In M. C. P Silva \& L. Solis-Ponton (Orgs.), Ser pai, ser mãe - parentalidade: um desafio para o terceiro milênio (pp. 29-40) São Paulo: Casa do Psicólogo.

Tenório, F. (2001). Da reforma psiquiátrica à cínica do sujeito. In A. Quinet (Org.), Psicanálise e Psiquiatria: controvérsias e convergências (Vol. 3, pp. 121-131). Rio de Janeiro: Rios Ambiciosos.

Tenório, F.(2002). A reforma psiquiátrica brasileira, da década de 1980 aos dias atuais: história e conceitos. História, Ciência, Saúde, 9(1), 25-59. doi: 10.1590/S0104-59702002000100003

Zornig, S. M. A-J. (2010). Tornar-se Pai. Tornar-se Mãe: o processo de construção da parentalidade. Tempo Psicanalítico, 42(2), 453-470. Recuperado de http://pepsic.bvsalud.org/scielo. php?pid=S0101-48382010000200010\&script=sci_abstract

1. Segundo Fontes (2010) é nos círculos sociais, por onde circulam os sujeitos, que sua rede de suporte vai ser ancorada. Esses campos de sociabilidade onde os sujeitos com um sofrimento psíquico podem encontrar apoio social estão localizados nas redes primárias ou/fortes (famílias, vizinhos, amigos) e nas redes secundárias ou/ fracas (ONGs, igrejas, CAPS). 
Loucura e abuso de substâncias psicoativas: Desinstitucionalização e as vicissitudes da parentalidade

Adilane dos Santos Barbosa, é Psicóloga graduada pela Universidade Federal da Bahia (UFBA).

Endereço para correspondência: Rua do Contorno, Quadra 8, Cia 1 -

Simões Filho (BA).

Telefones: (71) 3396-3065/ 99112-2280.

E-mail: adilanebarbosa@gmail.com

Vládia Jamile dos Santos Jucá, Doutora em Saúde Coletiva pela Universidade Federal da Bahia (UFBA), Pós-Doutorado em Teoria Psicanalítica pela Universidade Federal de Minas Gerais (UFMG), é Professora Adjunto III do Instituto de Psicologia da Universidade Federal da Bahia (UFBA) e Coordenadora da Graduação em Psicologia da Universidade Federal da Bahia (UFBA). E-mail: vladiajuca@gmail.com

Mônica de Oliveira Nunes de Torrenté, Médica Psiquiatra, PhD em Antropologia pela Universidade de Montreal (UofM), PósDoutorado em Antropologia na Universidade Paris V - Descartes,

é Professora Associado III do Instituto de Saúde Coletiva da Universidade Federal da Bahia (ISC-UFBA).

E-mail: monicatorrente11@gmail.com

Carla Mariana Sousa de Jesus, é Psicóloga Residente em Atenção à Saúde da Pessoa Idosa pela Escola Bahiana de Medicina e Saúde Pública (EBMSP) em parceria com as Obras Assistenciais Irmã Dulce.

E-mail: carlamarianapsi@gmail.com

Ueslei Solaterrar da Silva Carneiro, é Psicólogo Residente em Saúde Mental pelo Instituto de Psiquiatria -Universidade Federal do Rio de Janeiro (IPUB/UFRJ).

E-mail: uesleisolaterrar.17@gmail.com

Recebido em 16.Fev.16 Revisado em 26.Fev.17

Aceito em 02.Mai.17 